\title{
Measurement of Thermal Resistivity of Dune Sand Using a Field Thermal Probe
}

\author{
Ar. Priyanka Mehta ${ }^{1}$, Dr.Pulkit Gupta ${ }^{2}$, Ar. Anshu Agarwal $^{3}$, Dr. Rajesh Sharma ${ }^{4}$ \\ Asst. Professor, Department of Architecture and Town Planning, M.B.M Engg. College, Jodhpur, India ${ }^{1-4}$
}

\begin{abstract}
Estimation of soil thermal resistivity plays an important role for various engineering projects. Thermal resistivity of soil is a complex phenomenon that depends upon various parameters such as type of soil, particle size distribution, and compaction characteristics etc. Many researchers and investigators have tried to develop mathematical and theoretical models to estimate soil thermal resistivity. However, these models are not always capable of predicting thermal resistivity of soils. A laboratory thermal probe was fabricated to evaluate thermal resistivity of various soils. However, as natural soil consists of various size fractions ranging from clay to gravel, the laboratory thermal probe cannot be used very efficiently. This necessitated the fabrication of a field thermal probe that works on the principle of transient method and is a magnified version of the laboratory thermal probe. Based on the results obtained efforts have been made to develop generalized relationships for estimating the soil thermal resistivity of dune sand by knowing the dry density, moisture content and percent size fraction of the various particle sizes, and validation of the proposed generalized equations have been done with the results available in the literature.
\end{abstract}

Keywords: soil, dune sand, thermal resistivity, field thermal probe, transient method.

\section{INTRODUCTION}

Soil thermal properties are required in many areas of engineering, agronomy, and soil science. In recent years, considerable effort has gone into developing techniques to determine these properties. Thermal properties are necessary for modelling the transport of heat in soil. The heat capacity of a soil depends on several factors. These factors can be arranged into two broad groups, those which are inherent to the soil itself, and those which can be managed or controlled to a certain extent. Those factors or properties that are inherent to the soil include the mineralogical composition and the organic component of the soil. Factors influencing soil heat capacity that can be managed externally include water content and soil density [1,2,3]. Water content plays a major role in soil heat capacity but is the most difficult to manage. Soil management affects heat capacity because practices that cause soil compaction will increase the bulk density and decrease the porosity of a soil. This in turn will have a significant effect on heat capacity. Thermal resistivity of dune sand was studied with change in moisture content of soil and with change in density of soil using a field thermal probe.

\section{Dune SAND ANd IT's Properties}

Dune sands are primarily unconsolidated sediments formed by the erosion, transportation and deposition of the materials of weathering from the sandy parent material by the wind in the arid environment $[4,5,6]$. A vigorous and continuous deposition of these sands results into the formation of sand dunes, which have peculiar characteristics of changing their location, length and height, depending on the direction and intensity of the wind [7]. It has also been reported that the mineralogical and geo-morphological characteristics of the dune sands indicate their origin, type and process of formation [8].

They are structure less, loose and compact, calcareous, and non-calcareous and medium to fine grained. Dune sand at different slopes largely constitutes ( 70 to $85 \%$ ) fine sand of 0.02 to $0.2 \mathrm{~mm}$ followed by coarse sand (5 to $10 \%)$ of 0.2 to $2.0 \mathrm{~mm}$. The percentage of fine sand is higher (80 to $90 \%)$ on the leeward slopes than that of windward and flank slopes. It is due to the aerodynamic factor, which have carried dune sand particles to leeward slopes of the dunes leaving behind the coarse sand particle on the windward slopes. At certain locations the higher percentage of coarse sand on the leeward slopes of the dunes suggests that the local wind have played a significant role in depositing the coarse particles on these slopes. The significant variation in the texture of the soil on the different dune slopes has influenced their water holding capacity ranging from 20 to 26.3 percentage of the fine sand silt and clay display slightly greater range ( 23.5 to $26.3 \%$ ) of water holding capacity than the windward slopes, which show the lower range (20.9 to $25.5 \%$ ) of water holding capacity due to the quantity of coarse sand. It has been observed that there is a segregate variation in the chemical characteristics of the sand dune of different types. The content of calcium carbonate (CaCO3) varies from 0.3 to $2.1 \%$ at different slopes of dunes. The percentage of $\mathrm{CaCO} 3$ is higher $(0.7$ to $2.1 \%)$ on dune flanks than windward slopes. The higher percentage shows that dune flanks are comparatively more stable and less susceptible to wind erosion. These sands contain more than $80 \%$ of the particles that are in the size range of 0.05 to $0.25 \mathrm{~mm}$ [9]. 


\section{International Advanced Research Journal in Science, Engineering and Technology}

Vol. 8, Issue 9, September 2021

DOI: $10.17148 /$ IARJSET.2021.8906

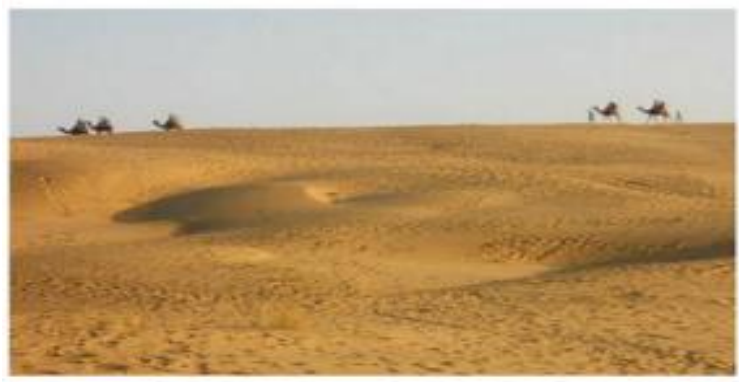

Jodhpur district is a part of Thar Desert. The dune sand used in the present study was brought from Osian, an ancient town located in Jodhpur district of Rajasthan state in western India. It is $67.7 \mathrm{~km}$ from Jodhpur. The sample of the dune sand were tested to obtain its grain size distribution by performing dry sieve analysis, according to IS 2720 (Part IV) 1965.Specific gravity of sand was obtained by density bottle method as per IS 2720 (Part II) -1980.The index properties of the soil sample of dune sand are listed in Table

Table 1 Index Properties of Dune Sand

\begin{tabular}{|l|l|l|}
\hline S. No & \multicolumn{1}{|c|}{ Property } & Values \\
\hline 1. & Specific gravity & 2.666 \\
\hline 2. & Natural moisture content (\%) & 0.603 \\
\hline & Size fractions & 0 \\
& coarse sand $(2-4.75 \mathrm{~mm})(\%)$ & 0.4 \\
& medium sand $(0.425-2 \mathrm{~mm})(\%)$ & 98.9 \\
& Fine sand $(0.075-0.425 \mathrm{MM})(\%)$ & 0.70 \\
\hline 4. & silt and clay< $<.075 \mathrm{~mm}(\%)$ & 0.145 \\
\hline 5. & Effective particle size( D10) & 1.517 \\
\hline 6. & Coefficient of uniformity (CU) & 1.01 \\
\hline
\end{tabular}

X-ray diffraction method is used for the identification of the minerals present in the soil. X-ray diffraction is a technique that provides detailed information about the atomic structure of crystalline substances. X-ray diffraction analysis uses monochromatic radiation. X-radiation at a specific wavelength can be produced. In the case of dune sand used for the research purpose XRD instrument (model: PAN analytical, x Pert Pro) is used with a specific wavelength. Figure 1 shows the X-ray diffraction spectra of the dune sand. (Reference : Material Development Laboratory Defence lab Jodhpur)

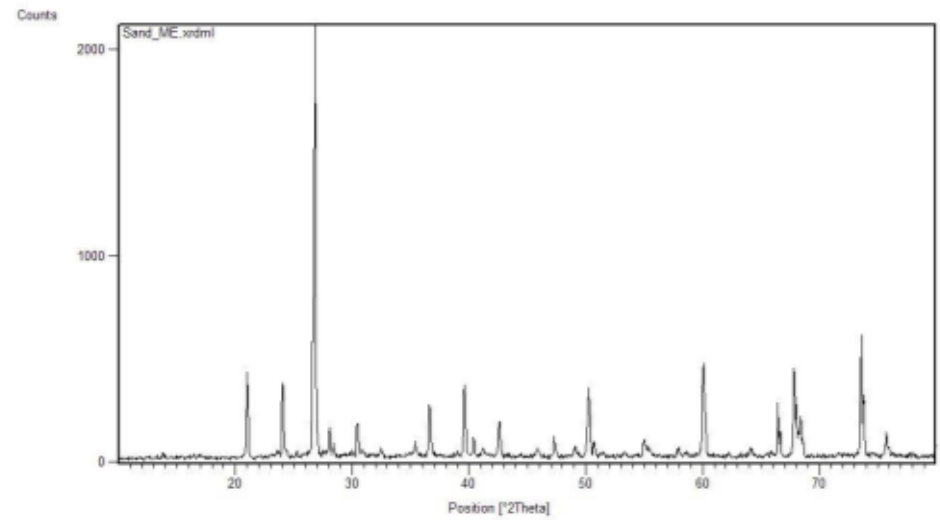

Figure 1 : X-Ray Diffraction Spectra of the Dune Sand 


\section{International Advanced Research Journal in Science, Engineering and Technology}

Vol. 8, Issue 9, September 2021

DOI: 10.17148/IARJSET.2021.8906

\section{TEST Procedure}

The thermal resistivity of soil at different moisture contents and densities was calculated using "Transient Method". Transient METHOD For ESTIMATION OF SOIL THERMAL RESISTIVITY

For rapid measurement of the soil thermal resistivity, transient method has been employed by many researcher It has been noticed that the method is quite convenient and to be adopted for accurate measurement. The method is based on the fact that the rate of temperature of heated body depends upon the thermal coefficient of the material in which it is buried. The basic assumption in this method is that the heating element is straight line of infinite length and infinitely small diameter. And it is embedded in a homogeneous and isotropic medium of infinite extent.

\section{Working Principle of The "FiEld Thermal Probe"}

A thermal probe approximates a line source of heat input of Q per unit length, of constant strength, in an infinite homogeneous soil medium maintained, initially at uniform temperature. Temperature at any point in the soil medium depends on the duration of heating and the soil thermal conductivity. In the mathematical form this can be presented as [10]:

$$
\frac{\partial \theta}{\partial t}=\alpha\left(\frac{\partial^{2} \theta}{\partial r^{2}}+\frac{1}{r} \cdot \frac{\partial \theta}{\partial r}\right)
$$

where $\theta$ is units temperature of the soil mass, $\mathrm{t}$ is the time of heating, $\alpha$ is the thermal diffusivity constant $(=\mathrm{k} / \gamma \mathrm{Cp}), \mathrm{k}$ corresponds to the thermal conductivity (inverse of thermal resistivity $\mathrm{R}$ ) of the soil, $\mathrm{Cp}$ is the specific heat of the soil, $\gamma$ is unit weight of the soil, and $\mathrm{r}$ is the radial distance from the heat source. The temperature rise $\theta$, between the times $\mathrm{t} 1$ and $\mathrm{t} 2$ may be represented as:

$$
\Delta \theta=\frac{\mathrm{Q}}{4 \pi \mathrm{k}} \log _{\mathrm{e}}\left(\frac{\mathrm{t}_{1}}{\mathrm{t}_{2}}\right)
$$

As such, a plot of temperature against logarithm of time shows a straight portion of slope s that can be defined as:

$$
\mathrm{s}=\frac{\mathrm{Q}}{4 \pi \mathrm{k}}=\frac{\mathrm{QR}}{4 \pi}
$$

and

$$
\mathrm{Q}=\mathrm{i}^{2} \xi
$$

where $\xi$ is the resistance per unit length of the probe and $i$ is the electrical current. It will be noted that the average property of the body entering this expression is the thermal conductivity and that the other terms in Eq. (3.3) are quantities readily measurable by the developed probes. Eq. (3.3) can be written as:

$$
R=\left(\frac{4 \pi}{i^{2} \xi}\right) x s
$$

\section{FABRication Details OF THE "Field THERMAL Probe"}

For measuring the thermal resistivity of the soil sample, a field thermal probe, as shown in Figure 2, has been fabricated. This probe works on the principle of the transient method.

The field thermal probe consists of a hollow copper tube of $1000 \mathrm{~mm}$ length with external and internal diameters of $12.5 \mathrm{~mm}$ and $12 \mathrm{~mm}$, respectively. Nichrome heater wire is used for heating the probe by passing current through it. $\mathrm{MgO}$ of very low resistance $(100 \times 10-6$ to $200 \times 10-6$ Q) is used as a filler material so as to ensure uniform dissipation of the heat generated. Three thermocouples: TC-1, TC-2 and TC-3 are provided, on the inner surface of the tube, at distances of $50 \mathrm{~mm}, 500 \mathrm{~mm}$ and $950 \mathrm{~mm}$, respectively, from the bottom of the probe, to measure temperature of the probe. 
Vol. 8, Issue 9, September 2021

DOI: 10.17148/IARJSET.2021.8906

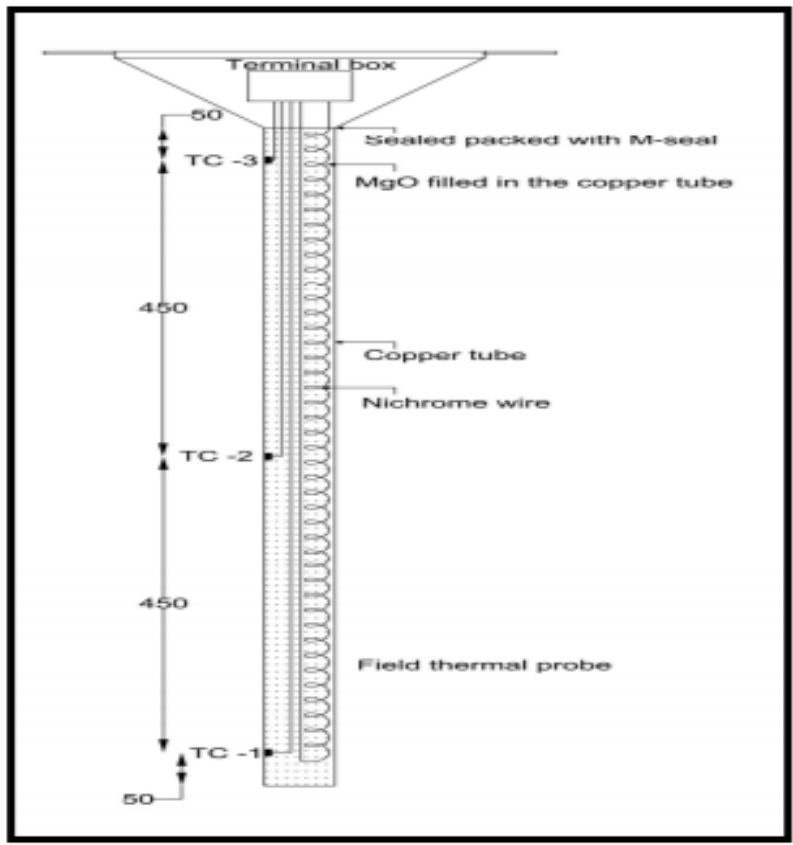

Figure 1.1 Section of the Field Thermal Probe

\section{EXPERIMENTAL SETUP}

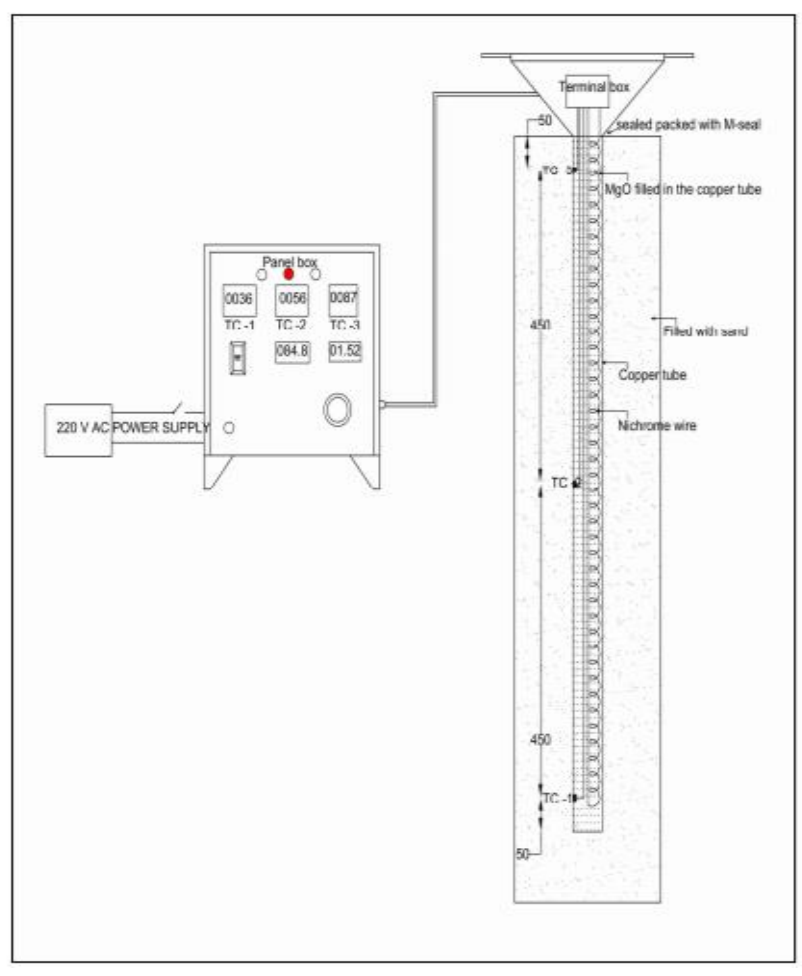

Figure 1.2 Experimental Setup Diagram

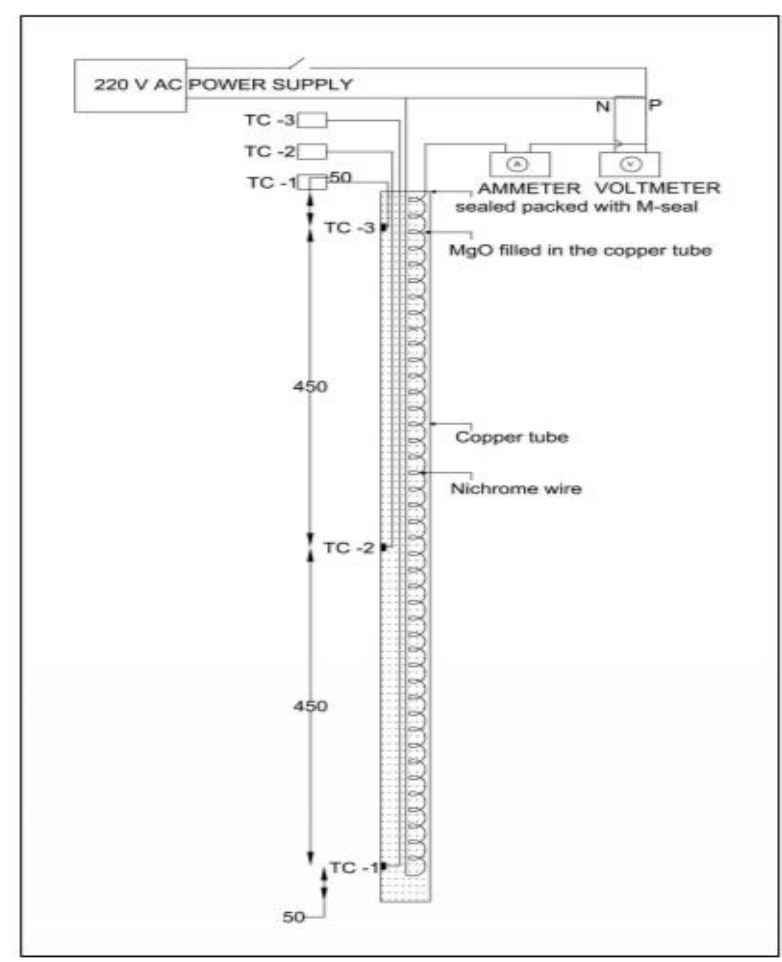

Figure 1.3 Circuit Diagram

For testing the thermal resistivity of the soil with the help of field thermal probe, the soil was compacted in a cylindrical container [High density polyethylene (HDPE), $1155 \mathrm{~mm}$ long and $223 \mathrm{~mm}$ in inner diameter]. By varying the number of layers and number of blows, the required dry density of the soil mass can be achieved. With the help of a dummy steel rod $(12 \mathrm{~mm}$ in diameter) a hole is made in the centre of the compacted soil mass for the insertion of the 


\section{International Advanced Research Journal in Science, Engineering and Technology}

Vol. 8, Issue 9, September 2021

\section{DOI: 10.17148/IARJSET.2021.8906}

field thermal probe. Later, the power supply is switched on and with the help of temperature readout unit, temperature of three thermocouples is measured as a function of time.

This procedure was adopted for determining the thermal resistivity of soil with variation in density and moisture content. Figure 3.6 shows the electrical panel which has an arrangement of a variable power supply to achieve the required temperature through variac, a digital ammeter placed in series with the nichrome wire to measure current, a digital voltmeter which measures the voltage, digital display board which give the readings of the temperatures of the three thermocouples TC-1,TC-2,TC-3.

Figure 1.2 shows the experimental setup in which the probe is inserted in the soil sample filled in the cylindrical container. The probe is connected to the electrical panel which is further connected to the A.C Supply. Figure 1.3 shows the circuit diagram of the experimental setup.

\section{Measurement of Thermal Resistivity of Dune Sand using Field Thermal Probe}

Every set of experiment is of a duration of 1 hour and readings are recorded of the temperature of the three thermocouples after every interval of $5 \mathrm{~min}$. First graph is plotted between time and respective temperature of the three thermocouples TC-1, TC-2 and TC-3. The second graph is plotted between loge(time) and respective temperature of the three thermocouples TC-1, TC-2 and TC-3. The equation of curve is obtained from the second graph. The equation is then differentiated for obtaining the value of slope. Slope1, Slope2 and Slope3 are the values of slope for TC-1,TC-2 and TC-3 for different temperature values at different loge(time).The median of the slope is put in the equation below for calculating the thermal resistivity.

$$
\mathrm{R}=\left(\frac{4 \pi}{\mathrm{i}^{2} \xi}\right) \mathrm{Xs}
$$

Table 1: THERMAL RESISTIVITY OF SOIL WITH 2\% MOISTURE CONTENT WITH DENSITY OF SOIL AS 1.55

OBSERVATIONS

AMBIENT TEMPERATURE:

18OC HUMIDITY:45\%

CURRENT: $1.5 \mathrm{~A}$

VOLTAGE: $83.4 \mathrm{~V}$

DENSITY: $1.55 \mathrm{gm} / \mathrm{cm} 3$

MOISTURE CONTENT: $2 \%$

\begin{tabular}{|l|l|l|l|l|l|l|l|}
\hline TIME & TC-1 & TC- 2 & TC-3 & LOGe(TIME) & SLOPE 1 & SLOPE 2 & PE 3 \\
\hline $10: 40$ & 33 & 56 & 54 & 1.60 & 8.75 & 23.51 & 19.77 \\
\hline $10: 45$ & 40 & 70 & 63 & 2.30 & 11.97 & 23.88 & 20.87 \\
\hline $10: 50$ & 45 & 79 & 69 & 2.70 & 13.85 & 24.10 & 21.51 \\
\hline $10: 55$ & 50 & 86 & 74 & 2.99 & 15.19 & 24.26 & 21.96 \\
\hline $11: 00$ & 53 & 91 & 76 & 3.21 & 16.23 & 24.38 & 22.31 \\
\hline $11: 05$ & 56 & 94 & 77 & 3.40 & 17.07 & 24.48 & 22.60 \\
\hline $11: 10$ & 59 & 96 & 79 & 3.55 & 17.79 & 24.57 & 22.85 \\
\hline $11: 15$ & 61 & 100 & 81 & 3.68 & 18.41 & 24.64 & 23.06 \\
\hline $11: 20$ & 63 & 102 & 82 & 3.80 & 18.96 & 24.70 & 23.24 \\
\hline $11: 25$ & 66 & 104 & 83 & 3.91 & 19.44 & 24.76 & 23.41 \\
\hline $11: 30$ & 67 & 107 & 85 & 4.00 & 19.89 & 24.81 & 23.56 \\
\hline $11: 35$ & 69 & 108 & 86 & 4.09 & 20.29 & 24.86 & 23.70 \\
\hline & & & & MEDIAN: & 17.43 & 23.69 & 22.72 \\
\hline & & & & RESISTIVITY: & 1.75 & 2.37 & 2.28 \\
\hline
\end{tabular}


Vol. 8, Issue 9, September 2021

DOI: 10.17148/IARJSET.2021.8906

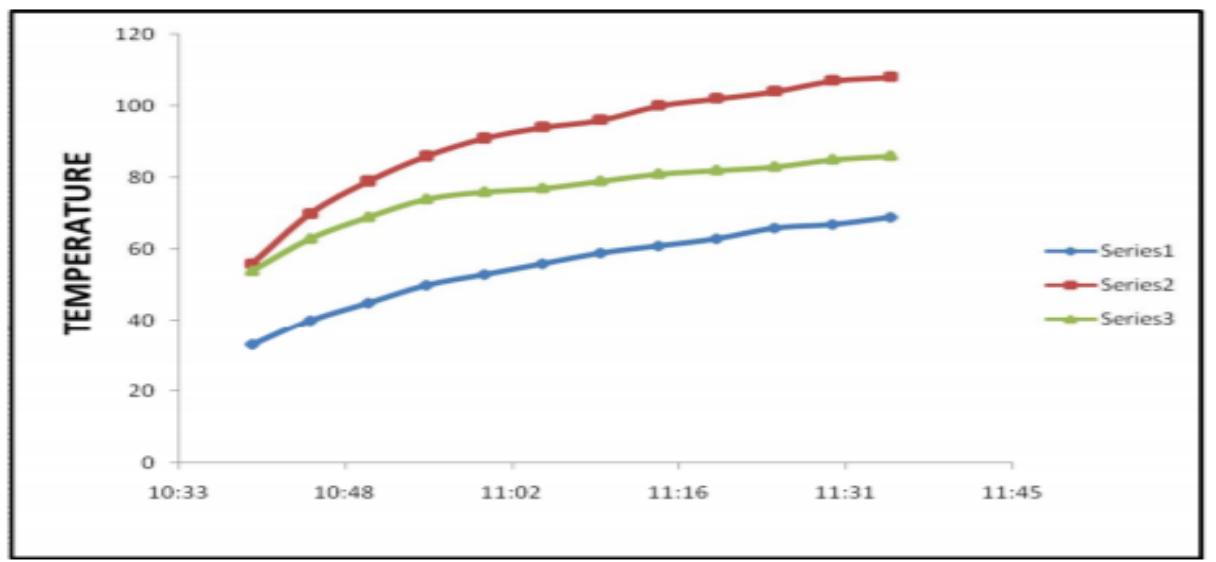

Figure 1.4 TIME VS TEMPERATURE

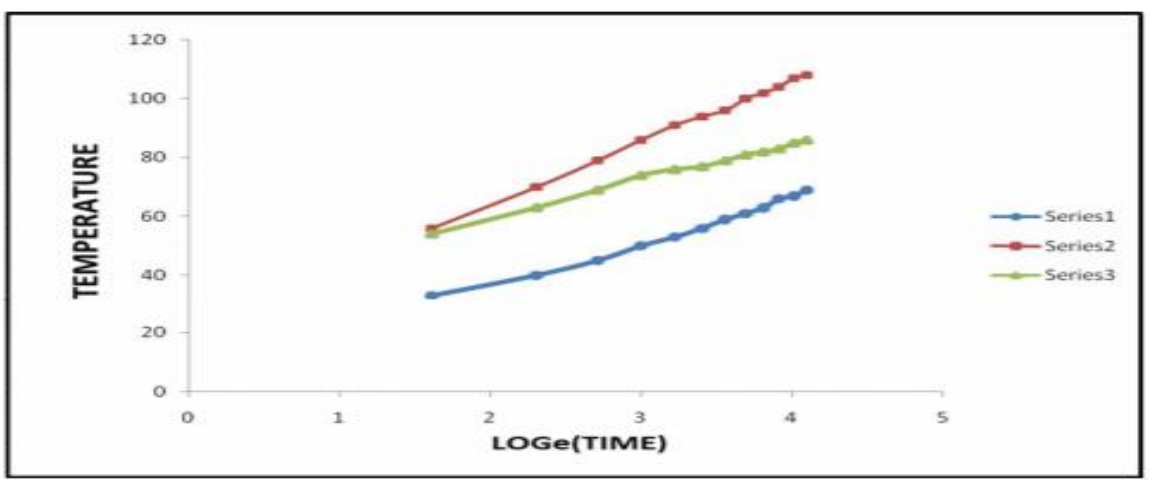

Figure 1.5 Loge TIME VS TEMPERATURE

Similarly thermal resistivity ratio is been calculated for $0 \%, 0.6 \%$ (N.M.C), $2 \%, 4 \%, 6 \%$ and $8 \%$ moisture content for all the three different densities $1.55 \mathrm{~g} / \mathrm{cm} 31.57 \mathrm{~g} / \mathrm{cm} 3$ and $1.59 \mathrm{~g} / \mathrm{cm} 3$. Thermal resistivity ratio is a new term which is been introduced as:Thermal Resistivity Ratio at $0.6 \%$ moisture content $=$ thermal resistivity at $0.6 \%$ moisture content/ thermal resistivity at $0 \%$ moisture content and in the similar way it is been calculated for $2 \%, 4 \%, 6 \%$ and $8 \%$ moisture content for all the three different densities $1.55 \mathrm{~g} / \mathrm{cm} 31.57 \mathrm{~g} / \mathrm{cm} 3$ and $1.59 \mathrm{~g} / \mathrm{cm} 3$. as shown in the tables and graphs below.

Table 2: Thermal Resistivity Ratio for Various Moisture Content of Soil with Density of Soil as $1.55 \mathrm{gm} / \mathrm{cm} 3$.

\begin{tabular}{|c|c|}
\hline MOISTURE CONTENT & RESISTIVITY RATIO \\
\hline $0.6 \%$ & 0.93 \\
\hline $2 \%$ & 0.74 \\
\hline $4 \%$ & 0.56 \\
\hline $6 \%$ & 0.42 \\
\hline $8 \%$ & 0.20 \\
\hline
\end{tabular}


International Advanced Research Journal in Science, Engineering and Technology

Vol. 8, Issue 9, September 2021

DOI: 10.17148/IARJSET.2021.8906

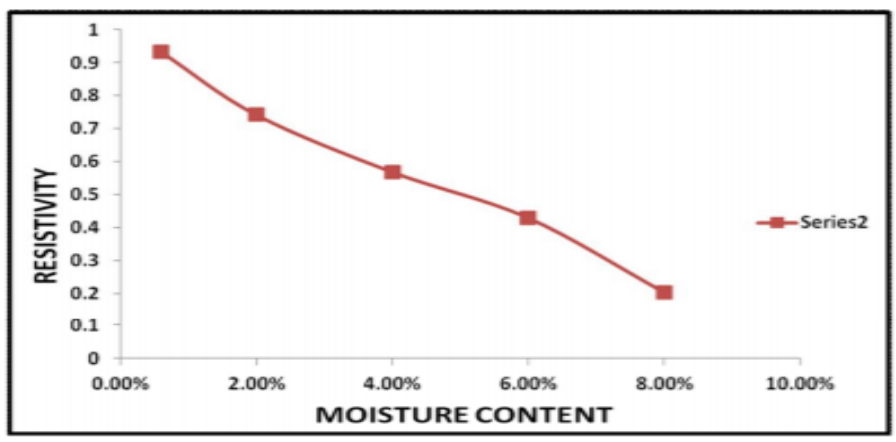

Figure 1.6 (Graph) : Moisture Content Vs Thermal Resistivity Ratio of soil with density of soil as 1.55 Table 3 : Thermal Resistivity Ratio for Various Moisture Content of Soil with Density of Soil as $1.57 \mathrm{gm} / \mathrm{cm} 3$.

\begin{tabular}{|c|c|}
\hline MOISTURE CONTENT & THERMAL RESISTIVITY RATIO \\
\hline $0.6 \%$ & 0.85 \\
\hline $2 \%$ & 0.60 \\
\hline $4 \%$ & 0.47 \\
\hline $6 \%$ & 0.33 \\
\hline $8 \%$ & 0.25 \\
\hline
\end{tabular}

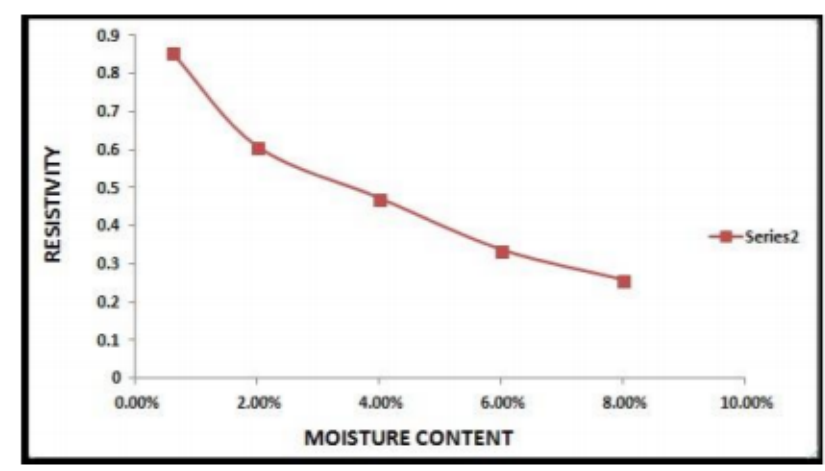

Figure 1.8 : Moisture Content Vs Thermal Resistivity Ratio for density of soil as $1.57 \mathrm{gm} / \mathrm{cm} 3$.

Table 4 : Thermal Resistivity Ratio for Various Moisture Content of Soil with Density of Soil as $1.59 \mathrm{gm} / \mathrm{cm} 3$.

\begin{tabular}{|c|c|}
\hline MOISTURE CONTENT & RESISTIVITY RATIO \\
\hline $0.6 \%$ & 0.90 \\
\hline $2 \%$ & 0.75 \\
\hline $4 \%$ & 0.68 \\
\hline $6 \%$ & 0.42 \\
\hline $8 \%$ & 0.25 \\
\hline
\end{tabular}




\section{International Advanced Research Journal in Science, Engineering and Technology}

Vol. 8, Issue 9, September 2021

DOI: 10.17148/IARJSET.2021.8906

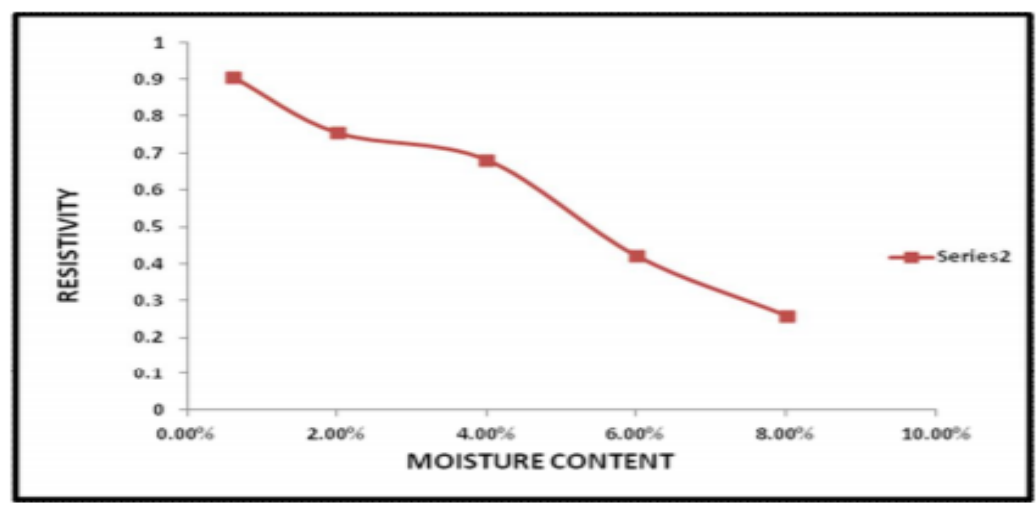

Figure 1.9: Moisture Content Vs Thermal Resistivity Ratio for Density of soil as $1.59 \mathrm{gm} / \mathrm{cm} 3$

In figure a graph is plotted between moisture content $(\%)$ and thermal resistivity for the three different densities of soil $1.55 \mathrm{~g} / \mathrm{cm} 31.57 \mathrm{~g} / \mathrm{cm} 3$ and $1.59 \mathrm{~g} / \mathrm{cm} 3$ which clearly shows the comparative analysis of change in thermal resistivity with change in moisture content and change in density of soil.

Table 5 : Thermal Resistivity of Soil for Various Moisture Contents for the three Different Densities of Soil

\begin{tabular}{|l|l|l|l|}
\hline \multirow{2}{*}{$\begin{array}{l}\text { MOISTURE } \\
\text { CONTENT }\end{array}$} & D1 (1.55) & D2 (1.57) & D3 (1.59) \\
\cline { 2 - 4 } & RESISTIVITY & RESISTIVITY & RESISTIVITY \\
\hline $0 \%$ & 2.87 & 2.14 & 2.04 \\
\hline $0.60 \%$ & 2.68 & 1.83 & 1.85 \\
\hline $2 \%$ & 2.13 & 1.3 & 1.54 \\
\hline $4 \%$ & 1.63 & 1.01 & 1.1 \\
\hline $6 \%$ & 1.23 & 0.72 & 0.86 \\
\hline $8 \%$ & 0.58 & 0.55 & 0.53 \\
\hline
\end{tabular}

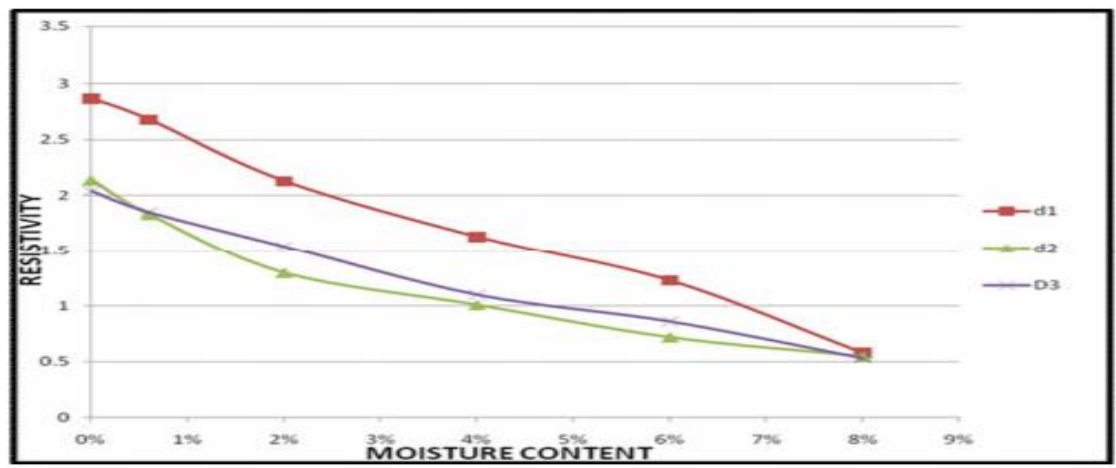

Figure 1.10: Moisture Content Vs Thermal Resistivity of Soil for the Three Different Densities of Soil

\section{CONCLUSION}

Based on the experimental results the following generalized conclusions can be made: (1) The field thermal probe can be used very efficiently for estimating thermal resistivity of different soils. (2) Since the conduction through soil is largely electrolytic, the amount of water present plays an important role in determining the resistivity. Normally, dry soils exhibit high resistivity because air, a poor conductor (resistivity equal to $4000^{\circ} \mathrm{C} \mathrm{cm} / \mathrm{W}$ ), separates the solid grains of the soil. If the moisture content of the soil increases, then the resistivity drops because water (resistivity equal to $165^{\circ} \mathrm{C} \mathrm{cm} / \mathrm{W}$ ) is a good conductor. As such, a saturated soil has lower resistivity than dry soil. The resistivity at first falls rapidly as the moisture content is increased, but beyond certain moisture content, the rate of decrease becomes much less. 3) With less air in the voids, the soil conducts heat better due to the following reasons: a) More heat is conducted through the individual soil grains because there are more of them to conduct heat. b) More heat is conducted 
International Advanced Research Journal in Science, Engineering and Technology

Vol. 8, Issue 9, September 2021

DOI: 10.17148/IARJSET.2021.8906

through the water alone because both the volume and the continuity of the water increase. c) More heat is conducted between the soil grains through the interstitial water because there is less air and more water between the particles.

\section{REFERENCES}

[1]. Wierenga P J; Nielsen D R; Hagan R M (1969). Thermal properties of soil based upon field and laboratory measurements. Soil Science Society of America Proceedings, 33, 354-360.

[2]. De Vries D A (1952). The Thermal Conductivity of Soil. Meded. Landbouwhogesch, Wageningen, p 52

[3]. Yadav M R; Saxena G S (1973). Effect of compaction and moisture content on specific heat and thermal capacity of soils. Journal Indian Society of Soil Science, 21, 129-132

[4]. Al-Sayari, S.S., Zolt, J.G., 1978. Quaternary period in Saudi Arabia. Coop. Res. Proj. Univ. Pet. Miner., Dhahran, Aust. Acad. Sci., Vienna.

[5]. Zhu, Z.D., 1985. Status and trend of desertification in northern China. Journal of Desert Research 5 (3), 3-11.

[6]. Watson, A., 1985. The control of windblown sand and moving dunes: review of the methods of sand control in deserts with observation from Saudi Arabia. Journal of Engineering Geology 18, 237-252.

[7]. Tsoar, H., 2001. Types of aeolian sand dunes and their formation. In: Balmforth, N.J., Provenzale, A. (Eds.), Geomorphological Fluid Mechanics. Springer, Berlin Heidel-berg New York, pp. 403-429.

[8]. Ahlbrandt, T.S., 1979. Textural parameters of aeolian deposits. In: McKee, E.D. (Ed.), A Study of Global Sand Seas United States Geological Survey Professional Paper, 1052, pp. 23-32.

[9]. Chen, L.H., 1992. Suggestion on aeolian sandy soil taxonomy. In: Gong, Z. (Ed.), Discussion on Soil Taxonomic Classification in China. Academic Press, Beijing, pp. 152-157.

[10]. W.A. Sinclair, F.H. Buller, C.B. Benham, Soil thermal resistivity, typical field values and calculation formulas-IV. Soil thermal characteristics in relation to underground power cables, AIEE Committee Report, 1960, pp. 820-832.

[11]. Priyanka Singh; Prasad L B. "A Comparative Performance Analysis of PID Control and Sliding Mode Control of Two Link Robot Manipulator". International Research Journal on Advanced Science Hub, 2, 6, 2020, 43-54. doi: 10.47392/irjash.2020.35 